DOI: https://dx.doi.org/10.24093/awej/vol12no4.25

Pp.387 -400

\title{
The Impact of Learning Environment on EFL Students' Academic Achievement: A study of Socio-Cultural Factors Affecting Academic Achievement
}

\section{Elmakki AMIRI}

Cultures, Representations, Education, Didactics and Engineering Laboratory, Dhar Mehraz, Sidi Mohamed Ben Abdellah University, Fez, Morocco

Corresponding Author: amiry.elmakki@gmail.com

\section{Abderrahim EI KARFA}

Department of English, Faculty of Letters and Human Sciences, Dhar Mehraz, Sidi Mohamed Ben Abdellah University, Fez, Morocco

Received: 8/13/2021

Accepted: 11/2/2021

Published:12/15/2021

\section{Abstract}

It is worth pointing out that learning a foreign language in a multicultural context is a long and complex undertaking. Several factors influence whether or not English as a Foreign Language (EFL) students can accurately perceive and produce the foreign language. These variables can potentially contribute to the success and, or failure in learning and acquiring a foreign language. Given the Moroccan educational system, the research provided minimal insight into the relationship between those factors and language achievement. The present study's aim, therefore, was to investigate the environmental factors that affect students' academic performance. It also aimed to find out how these variables affect students' academic achievements. To achieve this aim, data have been collected via open-ended questionnaires, and interviews addressed mainly to First Year Students of Master Programs, Department of English, FLDM, USMBA-Fez. The findings have shown that students' academic achievements were significantly positively/negatively linked with the environmental factors, namely societal, home/family and school/classroom variables. The findings also revealed that the more highly sophisticated the social environment is, the more likely it is to foster EFL students' academic achievements. In addition, the more similarity exists between the students' cultures, the more successful the learning is. This study also showed that the development of EFL proficiency is a product of contextual factors influence. As such, the study concludes with several implications that brought up for possible effective change in the future to enhance the learning environment atmosphere, boost students' academic achievements, and, therefore, achieve better results.

Keywords: academic achievement, culture, EFL Morrocan students learning environment, social factors

Cite as: AMIRI , E., \& El KARFA, A. (2021). The Impact of Learning Environment on EFL students' Academic Achievement: A study of Socio-Cultural Factors Affecting Academic Achievement. Arab World English Journal, 12 (4) 387-400.

DOI: https://dx.doi.org/10.24093/awej/vol12no4.25 


\section{Introduction:}

In the last few decades, the ever-increasing need for the best communication skills in foreign languages in general and English, in particular, has created a massive demand for English teaching around the world (Richards, 2006). The classroom environment in Moroccan higher institutions is a place that brings students belonging to different Moroccan regions, practicing different lifestyles, from diverse linguistic and cultural backgrounds. There is a great mingling of cultures, and this has some of its adverse effects. Learning a foreign language in a multicultural context, therefore, is a long and complex undertaking. Several factors influence whether or not EFL students can perceive and produce the foreign language accurately. Hence, multiple factors come to influence the academic performance of the students. The process of acquiring and learning a foreign language is significantly affected by many factors. As such, scholars and experts in the field of education classified them into internal and external variables. These factors have either positive or negative correlations with the student's quality of achievement.

In this context, the present study investigates the environmental factors that affect students' academic achievements. It also aims to find out how these variables affect students' academic achievements.

The study attempts to answer the following questions:

1. What are the environmental factors that affect EFL students' academic achievements?

2. To what extent do the environmental factors affect EFL students' academic achievements?

3. What are the impacts of the environmental factors on EFL students' academic achievements?

Utilizing a mixed-method approach, the current research examines the effect, which several environmental variables have upon learning English as a foreign language among master students at USMBA, FLDM- Fez. In this context, the present study investigates the environmental factors that affect students' academic achievements. It also aims to find out how these variables affect students' academic achievements.

\section{Literature Review}

\section{Learning Environment/Context}

For a better understanding of the theoretical issues in the influence of the environmental factors on EFL students' academic achievement, it is of crucial importance to shed some light on definitions that attributed to the term 'learning environment.' Although definitions and perspectives on the learning environment vary widely, most experts on the topic agreed that it includes school learning spaces, home learning spaces, and community learning spaces. According to the Glossary of Education Reform, the learning environment consists of backgrounds, conditions, circumstances, framework, setting, or situation. That is, it has societal, home/family, and school/classroom variables. It encompasses and extends the culture of a school or class to cover a wide variety of settings and protects the outdoor environment taking into account the vital role of emotions in learning. Learning environments, thus, have both a direct and indirect influence on students' academic achievement. In this respect, Lyons (1977) provided an inclusive definition to context:

"a theoretical construct in the postulation of which the linguist abstracts from the actual situation and establishes as contextual all the factors which, by virtue of their influence 
upon the participants in a language event, systematically determine the form, the appropriacy and the meaning of utterances" (p. 572).

In the same line of thought, the learning environment used in this study to refer to the physical, emotional, and cultural context in which learning takes place, the surrounding circumstances, and the atmosphere which affect learning. The setting either provides a healthy, comfortable, safe, and secure space for students or hinders effective performance.

\section{Social factors in EFL Learning}

Based on a significant body of literature, the social factors refer to those variables of social communities that have apparent effects on language acquisition, including the linguistic nature of the community, the political climate concerning bilingualism, the socio-economic status of the student, as well as the language-learning context.

To begin with, the linguistic nature of the community is one of the factors that are believed to affect learning a foreign language. It should not surprise that Morocco has always been known for its linguistic diversity; it is socially and linguistically diverse. This process of variety is made because of historical factors, including colonization and the effects of globalization. The Moroccan cultural and linguistic community is characterized by the successful usage of Arabic, Tamazight, Spanish, French, and English.

Importantly, Ennaji (2005) gives a history of the various factors behind multilingualism in Morocco. He sketches the complexity of the language situation before and after colonization and the factors that lead multilingual communities to show up, including migration, globalization, and colonialism. Furthermore, he intensively focused on the issues of Culture, Identity, and Language, stressing that the role of the mother tongue is significant for identity building. Moreover, he sheds light on the tension that exists between Tamazight and Arabic languages and cultures as well. In addition, as has been stressed earlier, the Moroccan policymakers have strongly promoted foreign languages in general and English and in particular. In this respect, the former minister of higher education in Morocco said in an interview with the Moroccan newspaper "AlYaoum" that English is the practical language for scientific research; hence, it is believed to be the solution of the educational system in the country. He claimed that the students who want to continue their study in the scientific stream, more specifically Engineering and Medicine, should acquire proficiency in English. Morocco has to adopt English as the primary foreign language in the educational system like many countries such as Spain, Portugal, and Romania. (Rohan, 2014).

Furthermore, It cannot be denied that the social and economic status of the students affects overall human functioning (abilities and outcomes). Morgan et al. (2009) claimed that low-class students develop academic skills slower than children from higher socio-economic status groups. In other words, high-class Moroccan students had the chance to have access and enroll in highly sophisticated private schools, meet native speakers in foreign countries, attend conferences and workshops, and so on. On the other hand, low socio-economic status students are less likely to have experiences that encourage the development of fundamental skills since they have fewer resources to draw on. 
Similarly, context in which a foreign language is taught and learned, has an apparent effect on the language learning process. In 1972, Dell Hymes was the first who advocates the importance of context in learning a foreign language. He claimed the necessity of knowing what happens outside the classroom to explain students' behaviors, performance, and achievement. He noted further that "the key to understanding language in context is to start not with language but with context ... [and then to] systematically relate the two" (p.19). Smith and Braine (1974) also highlighted the role of the cultural context in affecting students' second and foreign language learning.

Interestingly, the foreign language context in Morocco is formal; the English language is used mainly in the academic settings, business, and other formal contexts. This has a clear impact on students' achievement.

\section{Social theories and models of foreign language learning}

It is worth noting that several researchers in second language acquisition have investigated many contextual and psychological factors that significantly affect second language acquisition and learning. These researchers in the field provided their own models to explain how those variables contribute or hinder the process of students' foreign language achievement. The arguments provided differ considerably between those scholars. The most critical social theories and models that have been highlighted in the literature and deserve careful attention are Gardner's model and Clement's social context model.

\section{Gardner's Model (Social-Educational Model)}

The leading and prominent figure in this model was Gardner. The social-educational model is considered as the recent model that applies to both foreign and second language learning contexts. Gardner (1985) attempted to combine Carroll and Lambert's model, and therefore came up with his model called the social-psychological model. In this model, Gardner depicted the attitudes and motivation in learning a second language. In this regard, he stressed the role of four crucial elements that have tremendous and considerable effects on second language acquisition. These factors include:

- Social Milieu: by the social milieu, Gardner means the cultural environment that may significantly affect the cognitive and the affective aspects of the students.

- Individual differences: these differences have to do with four variables that interact with the context, and therefore influencing second language learning. Gardner's model linked Anxiety, language aptitude, intelligence, and motivation to proficiency in a second language.

- Learning acquisition context: it is the setting in which language learning occurs, either formal or informal. Indeed, the degree of proficiency differs significantly from one context to another.

- Outcomes: knowledge and language skills (e.g., grammar \& vocabulary) and non-linguistic skills (e.g., values and interest in the target language learning).

Succinctly stated, the four variables mentioned above directly affect second language learning. Gardner stressed that language aptitude and intelligence have significant influence 
when learning occurs in formal contexts, while motivation role is substantial in informal contexts.

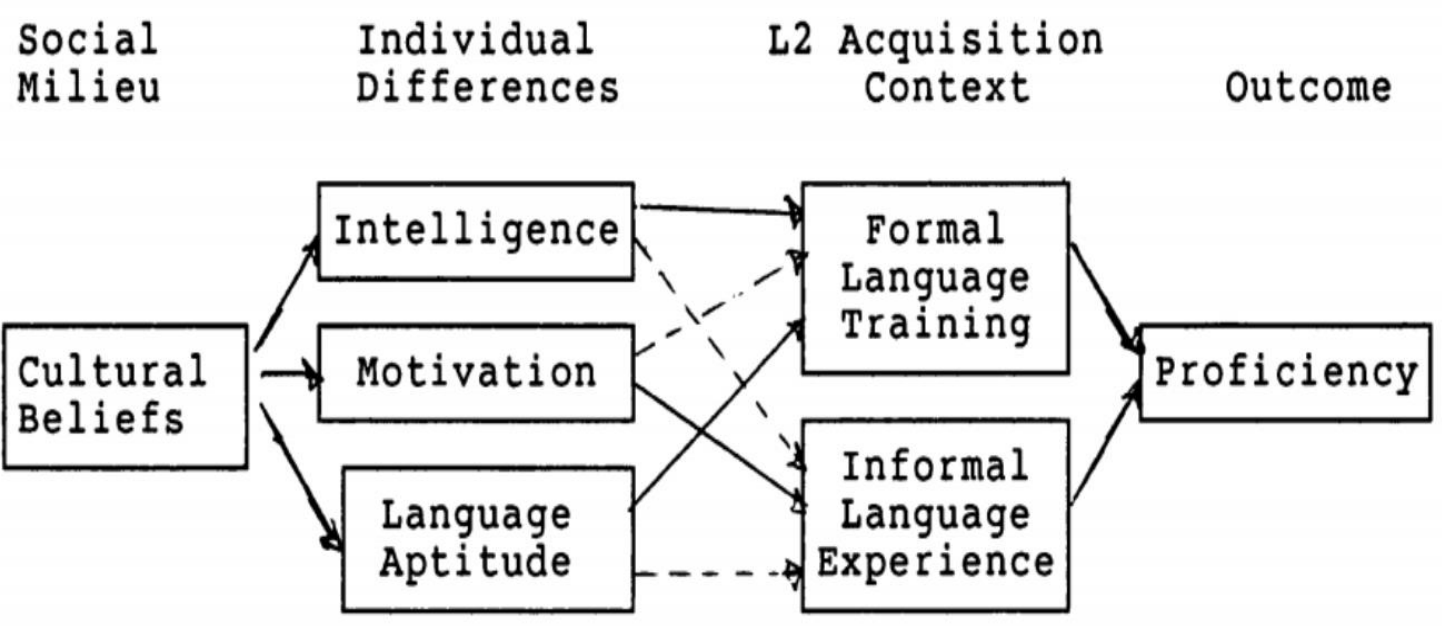

Figure 1. Operational Formulation of the Socio-Educational Model

\section{Clement's Model (Social Context Model)}

Clement's social context Model (1980) ensured the role of the cultural and the social environment on the communicative competence of the students, highlighting two different variables; integrativeness and fear of assimilation. By integrativeness, Clement meant holding a positive attitude towards the target language and culture, while the fear of assimilation has to do with the fear of losing one's own culture or the first language (Clement \& Kruidenier, 1985). This motivational process is called the primary motivational process. In addition, a second process was presented by Clement. It is called the secondary motivational process. This process plays a crucial role in the acquisition of learning a target language. It refers to the students' selfconfidence to use the target language (TL). Put it differently, the student has more chance to learn a target language and gains self-confidence if there is a pleasant contact. However, the failure will be the result of using the second language (L2) (Clement, 1980).

In short, the model introduced by Clement enhanced the idea that students' success or failure to acquire the target language is determined by the students' level of motivation. The latter is affected by the ethnolinguistic vitality of the second language(L2) and the level of confidence to use the L2. Therefore, Clement neglects the role of the school context and the classroom environment in learning the second language.

\section{Methodology}

To meet the study objectives, two main data collection methods were used: open-ended surveys and interviews. 


\section{Participants}

A total of 79 students originally participated in the study. They were Moroccan first-year master (MA) students at the University of Sidi Mohammed Ben Abdellah in Fez (USMBA). They were enrolled in the first year in four different Master Programs, namely Cultural Studies, Language, Communication \& Society, Translation, and Applied Language Studies \& Research in Higher Education. This population was chosen because students, in the four master programs, came from different cities bringing their own cultures that make the classroom a multicultural context. They came from twenty-five different cities, which are: Fez, Tinghir, Aknoul, Bouizakarne, Elhoceima, Outat Elhaj, Ksar Elkbir, Arfoud, Tafraout, Meknes, Misour, Rissani, Oujda, Tiznit, Houaya, Boulmane, Berkane, Casablanca, Ifrane, Rabat, Taza, Sefrou, and Agadir. Students' mother tongues vary widely between the four dominant languages (Moroccan Arabic, Tamazight, Tarifit, and Tachlhit (Tasousit). Furthermore, the great majority of the respondents, thirty-five out of seventy-nine, live in Fez. In addition, $76 \%$ of the respondents were aged between nineteen and twenty-four, $19 \%$ were aged between twenty-five and thirty, and 5\% were aged over thirty. There were forty-four (56\%) male participants, thirty-five (44\%) female participants.

\section{Research approach}

Both the qualitative and the quantitative approaches were used in this study. The quantitative approach helped determine the profiles of the EFL students whose proficiency is affected by the environmental variables, in measuring the extent to which their proficiency is affected, and in finding out the different factors behind and impacts of the environmental influence. On the other hand, the qualitative approach was helped elicit more in-depth explanations about why and how some EFL students' proficiency is influenced by the teaching/learning environment (either formal or informal). Mixing both approaches increased the validity and the reliability of the data and, thus, the quality of the findings.

\section{Data collection procedures:}

The first and main data collection procedure that was used to gather quantitative data is the questionnaire. It consisted of two parts related to the participants' background information and factors affecting EFL students' academic achievement. One of the strengths of using a questionnaire in this study was to elicit quantitative data related to the profiles of EFL students whose proficiency was affected by the environmental variables, and the reasons behind and impacts of the environmental influence on their proficiency. Moreover, semi-structured interviews were also used to collect data. This qualitative data collection procedure allowed respondents the time and scope to talk about their opinions on the subject. It allowed the researcher to elicit in-depth information around the topic.

\section{Results}

\section{Social community factors affecting EFL students' academic achievements}

In item six in the questionnaire, the participants were asked about the social community factors affecting the EFL students' academic achievements. They were given seven statements and asked to indicate whether they have positive, negative, or no effects on EFL students' academic achievements. They were also asked to add any other factor not mentioned in the list under the section other. The obtained results are summarized in Table 1 below. 
From the results presented, it can be seen that item one, "Linguistic Nature of the Community (Multilingualism) ," is believed to affect the EFL students' academic achievements positively. Sixty-two out of seventy-two respondents stressed that the presence of different local and foreign languages in Morocco leaves room for diversity and creates a good learning atmosphere that promotes students' learning outcomes and, therefore, their academic achievements. To substantiate this, interviewee one stressed that: "being in a multilingual society helps you become a bilingual, acquiring new skills, improving multitasking abilities, being more logical and rational, having better decision-making skills and being more perceptive and aware of your surroundings. Moreover, multilingualism may not affect the outcomes of the students. This view is held by twenty respondents. In this respect, an interviewee claimed that: "It (multilingualism) has nothing to do with the progress of students; all that matters is one's motivation and selfesteem as well some external factors." While only five respondents argued that Moroccan linguistic diversity has negative effects on students' academic achievements.

The study also reveals that the students who belong to a high socio-economic status get the chance to benefit from various facilities and thus affect their academic achievements positively while students low socioeconomic status students are less likely to have experiences that encourage the development of fundamental skills since they have fewer resources to draw on. Likewise, the figure above shows, in items two and three respectively, that the great majority of the respondents, fifty-nine out of seventy-nine, argued that the high socio-economic status of the students affects their outcomes of the students in a positive way. As such, fifty-eight out of seventy-nine pinpointed that the low socio-economic status of the students hinders the success of the EFL students. Similarly, one interviewee sign pointed that: "high-class students have the chance to have access to libraries, buy books, meet native speakers in foreign countries, attend conferences and workshops, and so on." This argument finds real evidence in Morgan et al. (2009), who claimed that low class-students develop academic skills slower than children from higher socio-economic status groups.

Interestingly, the great majority of respondents, fifty-five out of seventy-nine, argued that holding various beliefs, norms and values affects their achievement significantly. That is, being unfamiliar with others' cultures leads to culture shock. To give a further explanation to this point, one of the interviewees stated: "Yes, we came from different regions, and each one brings his/her cultural norms into the classroom. So, this hampers creating a safe learning environment in which all students express their thoughts, ideas, and beliefs freely". Here, we infer that learning about students' cultures beforehand helps minimize cultural misunderstanding and, therefore, culture shock. Moreover, twelve participants stressed the importance of culture shock in making students aware of the different cultures and ways to avoid the puzzling moments within the classroom context. As such, eleven claimed that culture shock does not affect their achievements. They do not identify culture shock as a component in the difficulties and variables that may affect students' academic achievements.

Importantly, when asked whether the English language learning context affects their achievements or not, forty-nine students firmly believe that learning English in a formal context boosts their personal and academic achievements. The formal context provides students with the basic and crucial skills to adapt themselves quickly to any situation. In addition, eighteen respondents hold the idea that learning English merely in a formal context is affecting EFL 
students' learning and achievements negatively. The English language is used mainly in academic institutions, business, and other formal environments. This, in fact, has a clear impact on students' achievement. One reason that would account for this is the following as an Interviewee signposted: "Yeah, the time allotted to English classes at the university is not enough. We need to practice the foreign language much more in the informal context. In other words, English should not be used only in the classroom environment to give the students the opportunity to have exposure to the authentic context to enhance their linguistic and communicative competencies." In addition, another interviewee said: "Yes, it somehow affects it negatively. Having the classroom as the only environment where I can use English can deteriorate the level of my spoken English. Therefore, the usage of the language shouldn't be limited to the classroom only." Added to this, eleven participants mentioned that there is no relationship, either positive or negative, between the English language-learning context and the performance of students. This view is confirmed by Clement (1980), who neglects the role of the school context and the classroom environment in learning the second language.

In addition, fear of the loss of one's own culture or L1 is chosen by thirty-six of the respondents as an environmental variable believed to affect students' academic achievements negatively. It is worth noting that maintaining one's own culture and neglecting the target lifestyles and cultural norms affects the outcome of the students in a variety of ways. Thirty-four of the respondents claimed that students' reluctance or even conservatism has no effect on their personal performance and proficiency. In this regard, one interviewee stated that: "I don't have a clear justification. I just don't think that students would fear to lose their L 1 since they keep using it at home and with friends." Only eight respondents mentioned the positive side of preserving one's own culture in the sense that it helps students to choose what suits and does not contradict their norms, traditions, and their beliefs.

Table 1. The effect of Social community factors on EFL students' academic achievement

\begin{tabular}{|l|l|l|}
\hline \multicolumn{2}{|c|}{ Items } & Count \\
\hline \multirow{3}{*}{ Linguistic Nature of the Community (Multilingualism) } & MISSING & 0 \\
\cline { 2 - 3 } & POSITIVE EFFECTS & $\mathbf{6 2}$ \\
\cline { 2 - 3 } & NEGATIVE EFFECTS & 5 \\
\cline { 2 - 3 } High Socioeconomic Status of the Student & NO EFFECTS & 12 \\
\cline { 2 - 3 } & MISSING & 0 \\
\cline { 2 - 3 } & POSITIVE EFFECTS & $\mathbf{5 9}$ \\
\cline { 2 - 3 } & NEGATIVE EFFECTS & 0 \\
\hline \multirow{3}{*}{ Low Socioeconomic Status of the Student } & MISSINGCTS & 20 \\
\cline { 2 - 3 } & POSITIVE EFFECTS & 0 \\
\cline { 2 - 3 } Culture Shock & NEGATIVE EFFECTS & 0 \\
\cline { 2 - 3 } & NO EFFECTS & $\mathbf{5 8}$ \\
\cline { 2 - 3 } & MISSING & 21 \\
\cline { 2 - 3 } & POSITIVE EFFECTS & 1 \\
\cline { 2 - 3 } Language Learning Context & NEGATIVE EFFECTS & $\mathbf{5 5}$ \\
\hline & NO EFFECTS & 11 \\
\cline { 2 - 3 } & MISSING & $\mathbf{4 9}$ \\
\hline
\end{tabular}


Arab World English Journal (AWEJ) Volume 12. Number 4. December 2021

he Impact of Learning Environment on EFL Students'

AMIRI \& El KARFA

\begin{tabular}{|l|l|l|}
\hline \multirow{3}{*}{ Fear to the Loss of One's Own Culture or L1 } & NEGATIVE EFFECTS & 18 \\
\cline { 2 - 3 } & NO EFFECTS & 11 \\
\cline { 2 - 3 } & MISSING & 1 \\
\cline { 2 - 3 } & POSITIVE EFFECTS & 8 \\
\cline { 2 - 3 } & NEGATIVE EFFECTS & $\mathbf{3 6}$ \\
\cline { 2 - 3 } & NO EFFECTS & $\mathbf{3 4}$ \\
\hline
\end{tabular}

\section{Perceptions of learning English in a multicultural context}

The participants were then given six statements and asked to indicate the degree of agreement or disagreement with each statement to elicit their perceptions of learning English in a multicultural context. The obtained results are summarized in the table below.

Table 2. Students' Perceptions of learning English in a multicultural context

\begin{tabular}{|c|c|c|}
\hline \multicolumn{2}{|l|}{ Items } & \multirow{2}{*}{$\begin{array}{ll}\text { Count } \\
0 \\
\end{array}$} \\
\hline \multirow{6}{*}{$\begin{array}{l}\text { The more similarity exists between the students' cultures, the } \\
\text { more successful the learning is. }\end{array}$} & MISSING & \\
\hline & STRONGLY AGREE & 33 \\
\hline & AGREE & 23 \\
\hline & NEUTRAL & 14 \\
\hline & DISAGREE & 7 \\
\hline & STRONGLY DISAGREE & 2 \\
\hline \multirow{6}{*}{$\begin{array}{l}\text { Acquiring English language proficiency necessitates the } \\
\text { adoption of cultural and linguistic aspects of English people. }\end{array}$} & MISSING & 0 \\
\hline & STRONGLY AGREE & 16 \\
\hline & AGREE & 33 \\
\hline & NEUTRAL & 11 \\
\hline & DISAGREE & 6 \\
\hline & STRONGLY DISAGREE & 13 \\
\hline \multirow{6}{*}{$\begin{array}{l}\text { Students try to achieve a sense of identification and } \\
\text { independence from others, based on some dimensions or values } \\
\text { such as language, norms, traditions... }\end{array}$} & MISSING & 0 \\
\hline & STRONGLY AGREE & 17 \\
\hline & AGREE & 37 \\
\hline & NEUTRAL & 21 \\
\hline & DISAGREE & 3 \\
\hline & STRONGLY DISAGREE & 1 \\
\hline \multirow{6}{*}{$\begin{array}{l}\text { Students' academic achievement has nothing to do with the } \\
\text { learning environment. }\end{array}$} & MISSING & 1 \\
\hline & STRONGLY AGREE & 1 \\
\hline & AGREE & 11 \\
\hline & NEUTRAL & 12 \\
\hline & DISAGREE & 24 \\
\hline & STRONGLY DISAGREE & 30 \\
\hline \multirow{6}{*}{$\begin{array}{l}\text { Students' academic achievement is affected by socio-cultural } \\
\text { aspects and variables. }\end{array}$} & MISSING & 1 \\
\hline & STRONGLY AGREE & 22 \\
\hline & AGREE & 39 \\
\hline & NEUTRAL & 14 \\
\hline & DISAGREE & 3 \\
\hline & STRONGLY DISAGREE & 0 \\
\hline \multirow{6}{*}{$\begin{array}{l}\text { learning about students' cultures beforehand helps achieve } \\
\text { proficiency }\end{array}$} & MISSING & 2 \\
\hline & STRONGLY AGREE & 25 \\
\hline & AGREE & 30 \\
\hline & NEUTRAL & 17 \\
\hline & DISAGREE & 5 \\
\hline & STRONGLY DISAGREE & 0 \\
\hline
\end{tabular}


From the results presented above, it is clear that item one, "The more similarity exists between the students' cultures, the more successful the learning is", got a high score. Fifty-six out of seventy-nine of the participants either strongly agreed or agreed with the statement in this item, while only a minority of them (nine participants) either disagreed or strongly disagreed with it. This may indicate that the differences in cultures indeed affect the process of learning and teaching. Certainly, negative attitudes and emotions are present due to unexpected cultural differences in the intra-cultural experiences and multicultural environment. Importantly, when learning a foreign language, EFL students tend to treat the new language in the lenses of their language. In this respect, an interviewee stated: "as you said, the cultural background is very important in the sense that students who belong to the same background stick with each other, collaborate and help each other significantly more than they do with others belonging to other cultures."

In addition, the results in the table above show that the vast majority of the participants, fortynine out of seventy-nine, were in favor of the statement in item two, "Acquiring English language proficiency necessitates the adoption of cultural and linguistic aspects of English people." While only nineteen disagreed or strongly disagreed with the statement, and the other eleven participants chose neutral. This demonstrates that language is the keystone of culture. That is, without language, culture would not be available. As such, language is widely influenced and shaped by culture (it reflects culture). Thus, culture is considered a crucial part of language teaching. Interestingly, the goal of learning a foreign language cannot be separated from its cultural context. In this line of thought, the linguist Lado(1964) stated that the goal of foreign language learning is:

"The ability to use it, understanding its meanings and connotations in terms of the target language and culture, and the ability to understand the speech and writing of natives of the target culture in terms of their great ideas and achievement" ( p. 25).

Therefore, teaching English as a foreign language inevitably involves the cultural teaching of that language.

The participants were also asked to indicate the degree of agreement or disagreement with the statement in item three "Students try to achieve a sense of identification and independence from others, based on some dimensions or values such as language, norms, traditions, and so on." The results show that the great majority (fifty-four of the respondents), either strongly agreed or agreed with the statement; only four students either disagreed or strongly disagreed with it, while twenty-one chose neutral. This demonstrates that the difference in cultural backgrounds pushes students to achieve a sense of identification and independence from other students who belong to different cultures. This may be because students find it challenging to accept other behaviors and norms, and preserve their own cultural norms and values, especially when there is no pleasant contact.

The results in table two also show that the vast majority of the participants either strongly disagreed or disagreed with item five, "Students' academic achievement has nothing to do with the learning environment." Fifty-four are strongly agreed and agreed with the statement in item six, "Students' academic achievement is affected by socio-cultural aspects and variables." This 
implies that societal, home/family, and school/classroom variables play a vital role in determining the degree of EFL students' academic achievements.

Unsurprisingly, fifty-five out of seventy-nine respondents either strongly agree or agree with the statement in item seven, "learning about students' cultures beforehand helps to achieve proficiency." This again can be explained by the fact that holding various beliefs, norms and values, and being unaware of the rules of social behaviors can affect the social relations of students as well as their academic achievements. Thus, it is of utmost importance to prepare as much beforehand as possible. That is to say, learning about other students' cultures and developing awareness of cultural background knowledge to be familiar with the new culture helps to achieve proficiency and creates a safe environment to overcome cultural obstacles. This familiarity with the new environment and its culture allows people to imagine the possible challenges they may face during their encounters to become more prepared.

\section{Discussion}

It is worth pointing out that the results obtained paint an image about the factors that can potentially contribute to the success and failure in learning and acquiring a foreign language. It is thus interesting to note that some of the results we get are not related to the findings in the literature. For example, Clement (1980) claimed, in his social context model, that students' success or failure to acquire the target language is determined by the students' level of motivation, which is affected by ethno-linguistic vitality of L2 and the level of confidence to use L2. Therefore, Clement neglects the role of the school/classroom environment in learning the second language. This argument was not found to apply to the context under our investigation. Instead, the vast majority of the respondents argued that not only motivation, but also the environmental variables affect their achievements significantly. On the other hand, several of the findings of this research corroborate the findings of some previous studies. In this vein, Schumann (1976) stressed that language is the factor in successfully acculturating. The acculturation model assumes that the more similarity exists between the two cultures, the more successful the learning is. Similarly, our data indicate the same idea and ensure that belonging to different cultures, holding various norms, traditions, and values has profound effects on students' academic achievements.

Moreover, in line with the research findings by Ferraro (1990), who pinpointed that the familiarity with the new environment and its culture allows students to imagine the possible challenges they may face during their encounters to become more prepared. This argument was also proved through our data. That is, learning about others' cultures beforehand to be familiar with the new cultures helps minimize culture shock and psychological disorientation and therefore allows students to achieve proficiency in foreign languages.

It is noteworthy that the faculty of letters and human sciences Dhar Elmahraz-Fez, more specifically the MA Programs received students from different cities and thus of diverse cultural backgrounds. In this regard, students of the four masters came from 25 different cities bringing their own cultures. This makes the classroom a multicultural context. Given this, this cultural diversity in which students come from diverse ethnic, linguistic and even racial backgrounds have either positive or negative effects on their academic achievements. Put it differently, they have different perspectives, insights; knowledge to the learning may be either beneficial or 
challenging. It enhances students' achievements through improving several skills, problemsolving, open minds, and increasing intercultural awareness through acquiring the ability to learn, and collaborate with students of diverse cultural backgrounds. On the other hand, the variation in traditions, norms, and beliefs pose significant learning limitations in this multicultural environment.

It is worth mentioning that socio-contextual factors, precisely societal, home/family, and school/classroom variables, in a way or another, significantly affect the whole paradigmatic and the pedagogic structure. The vast majority of the respondents emphasized the role of these variables in hindering the process of EFL learning. The fact that students come from different cultural backgrounds, hold various beliefs, norms, and values, are unaware of the rules of social behaviors, and learning a foreign language in another environment, is considered as a challenging task and the most influential variable that affects students' achievements. Therefore, intercultural adjustment and awareness help people understand the target culture and adapt to the new environment. This makes it a necessity to call for cross-cultural training that helps students understand their values as well as those of other sub-cultures EFL students in a multicultural context.

\section{Pedagogical recommendations}

Based on the obtained results, several implications can be brought up for possible effective change in the future. That is to enhance the learning environment atmosphere to boost the academic achievements of the EFL students and therefore achieve better results. In addition, for the higher education institutions to take steps towards more effective implementation, an intracultural communication course that includes several disciplines, should be demanded for EFL students. That helps students of different cultural backgrounds exchange information between them, interpreting the behaviors of other students in a more objective way and not heavily laden with emotion and values. It also gives a chance to all the students to learn about their peers' cultures beforehand to minimize the cultural misunderstanding and, therefore, the culture shock. Moreover, the university infrastructure should not be neglected when it comes to the external factors that profoundly affect students' achievements. The higher the infrastructure is, the more positive the impact on the students is. Last but not least, teachers have to be optimistic about diversity in the classroom; knowing the students as individuals as well as growing in cultural awareness is considered as the critical element of using students' diverse cultural backgrounds to enhance their academic achievement.

\section{Conclusions}

In the light of the study results and the ensuing discussion, several conclusions can be drawn. First, the linguistic nature of the community (Multilingualism) is believed to affect the EFL students' academic achievements positively. That is because different local and foreign languages in Morocco leave room for diversity and create a good learning atmosphere that promotes students' learning outcomes and, therefore their academic achievements. Moreover, holding various beliefs, norms, and values affects students' achievement in a significant way. The confusion about the norms of behavior in a new cultural setting hinders achieving better outcomes. As such, the fear of the loss of one's own culture or L1 is believed to affect students' academic achievements negatively. Furthermore, the more similarity exists between the students' cultures, the more successful the learning is. Finally, yet importantly, Cultural backgrounds push 
students to achieve a sense of independence from other students belonging to different cultures. Students find it challenging to accept other behaviors and norms as well as preserve their cultural norms and values, especially when there is no pleasant contact. The study also revealed that lowclass students develop academic skills slower than children from higher socio-economic status groups. In other words, the academic performance of students has been attributed to many factors that are mainly family-based (the high socio-economic status of the students have positive correlations with the student's quality of achievement and is negatively correlated with the low socio-economic level of their family).

Overall, it is worth noting, then, that the findings of this study showed that the development of EFL proficiency is a product of contextual factors influence. Several factors mentioned above were shown to correlate significantly with the EFL students' academic achievement at MA Program.

About the Authors:

Elmakki AMIRI is a $\mathrm{Ph}$. D. candidate conducting his research on the role of emotions in educational settings. He is a high school instructor of English. He is also a research assistant in British Council Gender-ing ELT project. He is the lead editor of the English teaching initiative internship (ETII) Morocco ESP Booklet. He also participated in different conferences and workshops on a wide range of topics. ORCID: https://orcid.org/0000-0001-6401-5285

Dr. Abderrahim EI KARFA is a professor of Applied Linguistics and Leadership, Department of English Faculty of Letters and Human Sciences, Dhar Mehraz Sidi Mohammed Ben Abdellah University, Fez, Morocco. He is a member of the University Council. He is also a member of the Faculty Council. As such, he is a former Director of the Research Laboratory: Language, Literature and Communication.

\section{References}

Clement, R. (1980). Ethnicity, contact and communicative competence in a second language. In H. Giles, P. Robinson, \& P. Smith (Eds.), Social Psychology and Language (pp. 147159). Pergamon Press.

Clement, R., \& Kruidenier, B. G. (1985). Aptitude, attitude and motivation in second language proficiency: A test of Clement's model. Journal of Language and Social Psychology, 4(1), 21 37. https://doi.org/10.1177/0261927X8500400102

Ennaji, M. (2005). Multilingualism, Cultural Identity, and Education in Morocco. New York: Springer.

Ferraro, G. (1990). The cultural dimension of international business. Englewood Cliffs J: Prentice-Hall

Gardner, R. C. (1985). Social psychology and second language learning: The role of attitudes and motivation. London: Edward Arnold Publishers.

Glossary of Education Reform (2019). Retrieved from https://www.edglossary.org/learningenvironment/

Hymes, D.H. (1972). On Communicative Competence. In Pride, J.B. and J. Holmes (Eds). Sociolinguistics. Selected Readings. Harmondsworth: Penguin, 269-293.

Lado, R. (1964). Language teaching, a scientific approach. New York: McGraw Hill, Inc. 
Lyons, J. (1977). Semantics. Volumes 1 and 2. Cambridge: Cambridge University Press.

Morgan, P. L., Farkas, G., Hillemeier, M. M., \& Maczuga, S. (2009). Risk factors for learningrelated behavior problems at 24 months of age: Population-based estimates. Journal of Abnormal Child Psychology, 37, 401-413.

Richards, J. C. (2006). Communicative Language Teaching Today, New York: Cambridge University Press.

Rohan, j. (Ed). (2014). Morocco's Minister of Education: French is No Longer Valid, English is the Solution. http://www.moroccoworldnews.com/2014/03/126856/moroccos-ministerof-education-french-is-no-longer-valid-english-is-the-solution/

Schumann, J. H. (1976). Social distance in second language learning. Language Learning.

Smith K.H. \& Braine, M.D.S. (1974). Miniature Language and Problems of Language Acquisition. In Bever, T.G. and W. Weksel (Eds.). Miniature Language and Problems of Language Acquisition. New York: Holt, Rinehart and Winston. 